\title{
Targeting thyroid cancer with acid-triggered release of doxorubicin from silicon dioxide nanoparticles
}

\author{
This article was published in the following Dove Press journal: \\ International Journal of Nanomedicine \\ 21 August 2017 \\ Number of times this article has been viewed
}

\author{
Shijie Li' \\ Daqi Zhang' \\ Shihou Sheng ${ }^{2}$ \\ Hui Sun' \\ 'Department of Thyroid Surgery, \\ ${ }^{2}$ Department of Gastrointestinal \\ Colorectal and Anal Surgery, \\ China-Japan Union Hospital \\ of Jilin University, Chang Chun, \\ People's Republic of China
}

Correspondence: Hui Sun Department of Thyroid Surgery, China-Japan Union Hospital of Jilin University, 126 Xiantai Street, Changchun 130000, People's Republic of China $\mathrm{Tel} / \mathrm{fax}+8643189876655$

Email sunhuil229@I63.com

\begin{abstract}
Currently, therapy for thyroid cancer mainly involves surgery and radioiodine therapy. However, chemotherapy can be used in advanced and aggressive thyroid cancer that cannot be treated by other options. Nevertheless, a major obstacle to the successful treatment of thyroid cancer is the delivery of drugs to the thyroid gland. Here, we present an example of the construction of silicon dioxide nanoparticles with thyroid-stimulating-hormone receptortargeting ligand that can specifically target the thyroid cancer. Doxorubicin nanoparticles can be triggered by acid to release the drug payload for cancer therapy. These nanoparticles shrink the tumor size in vivo with less toxic side effects. This research paves the way toward effective chemotherapy for thyroid cancer.
\end{abstract}

Keywords: thyroid cancer, silicon dioxide nanoparticle, doxorubicin, acid-triggered release

\section{Introduction}

Thyroid cancer is a rare disease where the tumor is located within the thyroid gland. ${ }^{1-3}$ Currently, thyroid cancer is mainly treated by surgery and radioiodine therapy (I-131 therapy) due to the excessive need for absorption and concentration of iodine in thyroid cells. ${ }^{4-6}$ Besides surgery and radioiodine therapy, chemotherapy - although uncommonly used for the treatment of thyroid cancer - could be used in combination with external beam radiation therapy for anaplastic thyroid cancer and other advanced cancers that are untreatable by other treatments. ${ }^{7,8}$ One major obstacle in thyroid cancer treatment is the specific delivery of the required drug to the thyroid gland, making drug delivery extremely essential and critical in this particular cancer.

It is well known that the thyroid-stimulating hormone receptor (TSHr), a glycoprotein G-protein-coupled receptor, is overexpressed in the plasma membrane of thyrocytes, especially in aggressive thyroid tumors. ${ }^{9-13}$ TSHr can specifically bind the thyroid-stimulating hormone (TSH). This specific binding behavior of TSHr with TSH can be adapted for generating a nanoparticle (NP) drug-delivery system to target thyroid cancer. ${ }^{14,15}$ Indeed, liposomes with gemcitabine and lipid/polymer NPs with cisplatin were developed and TSH was introduced onto these NPs for targeting thyroid cancer. Elevated anticancer effect and increased thyroid localization of the NPs were reported. ${ }^{14-16}$ However, to further reduce the side effects but to increase the therapeutic efficacy of NPs, triggered release of the anticancer drug is much more desirable. ${ }^{17-25}$

\section{Materials and methods}

Doxorubicin, (Dox) cis-aconitic anhydride, and silicon dioxide $\left(\mathrm{SiO}_{2}\right)$ with amine group $\left(\mathrm{NH}_{2}\right)$ groups on the surface were purchased from Sigma-Aldrich. Thyroidstimulating hormone (TSH) (from human pituitary), 5-carboxyfluorescein ( $5^{\prime}$-FAM), 
succinimidyl ester (SE) were also purchased from SigmaAldrich Co. (St Louis, MO, USA). Succinimidyl carboxyl methyl ester (mPEG-NHS) and orthopyridyl disulfide PEG Succinimidyl ester (PDP-PEG-NHS) were purchased from Creative PEGWorks (Chapel Hill, NC, USA). All other chemicals were of reagent grade.

\section{Preparation of $\mathrm{SiO}_{2} / \mathrm{Dox}$ and $\mathrm{TSH}_{-} \mathrm{SiO}_{2} / \mathrm{Dox}$}

PEGylating of the $\mathrm{SiO}_{2} \mathrm{NPs}\left(\mathrm{SiO}_{2} @ \mathrm{PEG}\right)$

First, $\mathrm{SiO}_{2}(5 \mathrm{mg})$ with $\mathrm{NH}_{2}$ groups on the surface was dispersed in water in a flask, to which $\mathrm{mPEG}-\mathrm{NHS}(20 \mathrm{mg})$ was added. The reaction mixture was stirred for $6 \mathrm{~h}$ and subjected to dialysis against water in a dialysis bag (molecular cut-off 3,000 Da).

\section{Synthesis of Dox-COOH}

Doxorubicin hydrochloride (5 mg) was dissolved in dry dimethyl sulfoxide (DMSO) at room temperature in a dry glass bottle. Hereafter, $5 \mu \mathrm{L}$ trimethylamine and cis-aconitic anhydride $(1.3 \mathrm{mg})$ were added with stirring. The reaction mixture was stirred overnight and left for conjugation with $\mathrm{SiO}_{2}$ NPs without further purification.

\section{Preparation of Dox-loaded $\mathrm{SiO}_{2} \mathrm{NPs}$ ( $\left.\mathrm{SiO}_{2} @ \mathrm{Dox}\right)$}

The DMSO solution containing Dox-COOH prepared in the previous step was used directly for 1-Ethyl-3-(3-dimethylaminopropyl)carbodiimide and n-hydroxysuccinimide (EDC/NHS) activation. EDC (3.2 mg) and NHS (2 mg) was added to the Dox-COOH solution for $2 \mathrm{~h}$. The activated Dox-COOH was further poured into the $\mathrm{SiO}_{2} @$ PEG solution purified by dialysis. The reaction mixture was stirred for $6 \mathrm{~h}$ and subjected to ultracentrifugation and washing several times with phosphate buffered saline (PBS) to remove the un-reacted Dox-COOH. The unreacted Dox-COOH was collected and quantified by UV-Vis spectrometry.

\section{Preparation of TSH-targeted Dox-loaded $\mathrm{SiO}_{2} \mathrm{NPs}\left(\mathrm{TSH}-\mathrm{SiO}_{2} @ \mathrm{Dox}\right)$}

The preparation of TSH-SiO $@$ @Dox was similar to that of un-targeted $\mathrm{SiO}_{2} @$ Dox. A difference is in the preparation of $\mathrm{SiO}_{2} @$ PEG. During the preparation process, instead of using only mPEG-NHS, both PDP-PEG-NHS (2 mg) and mPEG-NHS (18 mg) were used. The conjugation of Dox is the same. The unreacted Dox-COOH was collected and quantified by UV-Vis spectrometry. To conjugate TSH to the NPs, they were first treated with $50 \mathrm{mM}$ dithiothreitol
(DTT) solution for $30 \mathrm{~min}$. To remove the free DTT, the NPs were ultracentrifuged and washed several times. Thereafter, TSH was added into the solution for ligand conjugation. The NPs thus prepared were collected by ultracentrifugation, and the unconjugated TSH was removed by washing away. The unconjugated TSH could be quantified by enzyme-linked immunosorbent assay (ELISA).

\section{Characterization of NPs by dynamic light scattering (DLS) and transmission electron microscopy (TEM)}

The size and zeta potential of the NPs prepared was measured by Zetasizer ZS Nano (Malvern Instruments, Malvern, Worcestershire, UK). The morphology of the NP was observed using a JEOL JEM-200CX instrument (JEOL, Tokyo, Japan).

\section{Acid-triggered release of Dox from the NPs}

The release of Dox from the NPs was performed using a dialysis method: $5 \mathrm{~mL}$ TSH-SiO$/ 2$ Dox at a known Dox concentration was put into a dialysis bag (molecular cut-off 3,000 Da). The dialysis bag was thoroughly sealed against any leakage. To monitor the release of Dox, two buffered solutions were used. One was acetate-buffered solution at $\mathrm{pH} 5.0$ and the other was PBS at $\mathrm{pH}$ 7.0. The dialysis bag was dialyzed against $50 \mathrm{~mL}$ of buffered solution. At a preferable time point, $300 \mu \mathrm{L}$ of solution was collected for UV-Vis absorbance measurement. The cumulative Dox release was calculated.

\section{Cell lines}

FTC-133 human follicular thyroid carcinoma cells were purchased from Sigma Aldrich, and Chinese hamster ovary (CHO) cells were provided by the American Type Culture Collection (Manassas, VA, USA). CHO cells with TSHr $\left(\mathrm{CHO} / \mathrm{TSHr}^{+}\right)$and $\mathrm{CHO}$ cells without $\mathrm{TSHr}\left(\mathrm{CHO} / \mathrm{TSHr}^{-}\right)$ cell lines were grown in nutrient mixture F-12 medium with $10 \%$ fetal bovine serum and $1 \%$ penicillin-streptomycin $(\mathrm{P} / \mathrm{S})$. Moreover, FTC-133 thyroid cancer cells were incubated in Dulbecco's Modified Eagle Medium/nutrient mixture F-12 supplemented with glutamate, D-glucose, pyruvate, and other regular ingredients of normal growth media. The cells were grown in ambient conditions, the media was changed, and cells were sub-cultured from time to time.

\section{Intracellular uptake of $\mathrm{SiO}_{2} @ \mathrm{Dox}$ and TSH-SiO @Dox by $\mathrm{CHO} / \mathrm{TSHr}^{+}$and $\mathrm{CHO} / \mathrm{TSHr}^{-}$cells}

$\mathrm{CHO} / \mathrm{TSHr}^{+}$and $\mathrm{CHO} / \mathrm{TSHr}^{-}$were seeded in six-well plates at 0.5 million cells per well overnight. $\mathrm{SiO}_{2} /$ Dox and 
TSH-SiO $/ 2$ Dox at $5 \mu \mathrm{g}$ Dox/mL were added to the wells, respectively, with PBS as a control. After $3 \mathrm{~h}$, the cells were thoroughly washed by PBS three times and then the cells were trypsinized and collected and fixed by $4 \%$ paraformaldehyde. The fluorescence from Dox can be measured by flow cytometry (BD Biosciences, Franklin Lakes, NJ, USA) gated by the PBS-treated group.

\section{Competitive uptake inhibition of TSH- $\mathrm{SiO}_{2} @ \mathrm{Dox}$ by blocking with free TSH}

$\mathrm{CHO} / \mathrm{TSHr}^{+}$cells were seeded in six-well plates at 0.5 million cells per well overnight. Prior to NP treatment, free TSH (10 $\mu \mathrm{U} / \mathrm{mL}$ ) was added to each well to block the surface TSHr. Thereafter, $\mathrm{SiO}_{2} / \mathrm{Dox}$ and $\mathrm{TSH}-\mathrm{SiO}_{2} / \mathrm{Dox}$ at $5 \mu \mathrm{g}$ Dox $/ \mathrm{mL}$ were added to the wells, respectively, with PBS as a control. After $3 \mathrm{~h}$, the cells were thoroughly washed by PBS three times and then trypsinized and collected before fixation by $4 \%$ paraformaldehyde. The fluorescence from Dox can be measured by flow cytometry (BD Biosciences, Franklin Lakes, NJ, USA), gated by the PBS-treated group.

\section{TSH-SiO $@$ Dox by flow cytometry and confocal laser scanning microscopy}

To study the co-localization of the NPs and the drug Dox, NPs were first labeled with $5^{\prime}$-FAM by incubating with 5'-FAM-NHS. Un-reacted 5'-FAM was washed away by ultracentrifugation. FTC-133 cells were seeded in six-well plates at a density of 0.5 million per well. Cells were then treated with $\mathrm{TSH}-\mathrm{SiO}_{2} / \mathrm{Dox} / 5^{\prime}$-FAM, with PBS as a control. After $3 \mathrm{~h}$, the cells were thoroughly washed by PBS three times and then trypsinized and collected prior to being fixed by $4 \%$ paraformaldehyde. The fluorescence from Dox (red) and 5'-FAM (green) can be measured by flow cytometry (BD Biosciences).

To study the co-localization of Dox (red) and the NPs by $5^{\prime}$-FAM (green), confocal laser scanning microscopy was used. FTC-133 cells were seeded in six-well plates with a cover slide at a density of 0.2 million per well. Cells were then treated with $\mathrm{TSH}-\mathrm{SiO}_{2} / \mathrm{Dox} / 5^{\prime}$-FAM. After $3 \mathrm{~h}$, the cells were thoroughly washed by PBS three times and stained by Hoechst 3342, fixed by $4 \%$ paraformaldehyde. The co-localization of drug and NPs can be visualized by Dox (red) and 5'-FAM (green) via confocal laser scanning microscopy (FLV-1200).

\section{In vitro cytotoxicity study}

FTC-133 cells were seeded in 96-well plates overnight. The cells were then treated with free Dox, $\mathrm{SiO}_{2} @ \mathrm{Dox}$, and TSH-SiO $@$ @Dox at a preferable drug concentration. After
$72 \mathrm{~h}, 10 \mu \mathrm{L}$ of $5 \mathrm{mg} / \mathrm{mL}$ MTT solution (PBS) was added into each well. After incubation for $4 \mathrm{~h}, 100 \mu \mathrm{L}$ acidified sodium dodecyl sulfate solution was added into each well. Overnight, the absorbance at $570 \mathrm{~nm}$ of each well was read by a microplate reader. Background absorbance at $650 \mathrm{~nm}$ was also read and subtracted.

\section{Colony formation assay}

FTC-133 cells were seeded in six-well plates at a density of 2,000 cells per well overnight. Cells were then treated with free Dox, $\mathrm{SiO}_{2} @$ Dox, and TSH-SiO $@$ Dox at a concentration of $0.05 \mu \mathrm{M}$. The cells were then left to grow for 2 weeks. Colonies were fixed with glutaraldehyde $(6.0 \% \mathrm{v} / \mathrm{v})$ and stained with crystal violet $(0.5 \% \mathrm{w} / \mathrm{v})$ for $30 \mathrm{~min}$. The cells were then thoroughly washed by water. The colonies were counted using a stereomicroscope.

\section{Apoptosis}

FTC-133 cells were seeded in six-well plates at a density of 0.5 million cells per well overnight. Cells were then treated with free Dox, $\mathrm{SiO}_{2} @$ Dox, and TSH-SiO $@$ Dox at a concentration of $10 \mu \mathrm{M}$ for $24 \mathrm{~h}$. Cells were then washed by PBS three times, trypsinized, and stained by an Annexin-V/ fluorescein isothiocyanate apoptosis kit (Abcam, Cambridge, UK). The apoptosis was measured by flow cytometry.

\section{Use of animals}

The animal study was approved by the Bai Qiu En Medical Committee on Animal Use of the China-Japan Union Hospital and was carried out in accordance with the ChinaJapan Union Hospital animal protocol and guidelines (2016SSH0816) for the welfare and ethics of experimental animals. All animals were grouped and housed in cages, provided free access to standard diet and water, and raised under constant conditions.

\section{In vivo anticancer efficacy study}

NOD SCID mice were used to develop the thyroid cancer model. FTC-133 cancer cells at a density of 2 million were subcutaneously injected into the right flank of mice. When the tumor grew to $\sim 200 \mathrm{~mm}^{3}$, treatment was started. Mice were randomly grouped into four groups, with six mice in each group $(\mathrm{n}=6)$. They were treated with PBS (control), free Dox, $\mathrm{SiO}_{2} @$ Dox, and TSH-SiO $@$ @Dox at a dose of $5 \mathrm{mg}$ Dox $/ \mathrm{kg}$ body weight. Mice were treated at days 0,6 , and 12 . Tumor size was measured by callipers, and body weight was monitored every 2 days. The tumor size was calculated by the equation: ${ }^{40-42}$

$$
V=0.5 \times L \times W^{2}
$$


where $V$ is the volume of tumor, $L$ and $W$ are the longest and shortest diameter of the tumor, respectively. At the end of the study, tumors in each group were collected and weighed. For the cardiotoxicity study by creatinine kinase (CK) measurement, healthy 4- to 6-week-old Balb/c mice were purchased. Mice were randomly grouped into four groups with three mice in each group $(n=3)$. They were treated with PBS (control), free Dox, SiO $@$ @Dox, and TSH-SiO $@$ Dox at a dose of 5 mg Dox/kg body weight. Mice were treated at days 0 and 6 , killed after 2 weeks, and blood samples were collected.

\section{Statistical analyses}

Data are expressed as mean \pm standard deviation (SD). Statistical analysis was performed using the Student's $t$-test. Significance is defined as by ${ }^{\#} P>0.05,{ }^{*} P<0.05,{ }^{*} P<0.01$, and $* * * P<0.001$.

\section{Results and discussion}

Here, we describe a silicon dioxide NP for acid-triggered release of Dox for thyroid cancer therapy. Following a wellreported strategy, Dox was firstly conjugated to cis-aconitic anhydride and this Dox prodrug (Dox-COOH) ${ }^{26}$ was further conjugated to a PEGylated silicon dioxide $\mathrm{NP}\left(\mathrm{SiO}_{2}\right)$. For thyroid targeting, TSH was linked to NPs via disulfide bond formation (Scheme 1). The TSH-SiO $@$ @Dox thus prepared then showed excellent targeting to the thyroid cancer, with enhanced cytotoxicity and antitumor effect in vivo.

Initially, TSH-SiO $@$ Dox NPs were characterized by TEM and DLS. Representative images and curves are shown in Figure 1A and B. TSH-SiO $@$ @Dox-NPs were spherical in morphology, with a mean diameter of $35 \mathrm{~nm}$ on TEM. DLS showed that TSH-SiO $@$ @Dox-NPs measured 68 nm in diameter, corresponding to the TEM result. The size discrepancy between TEM and DLS may be due to the dried samples for TEM as compared to the more stretched NPs tested in solution for DLS. By monitoring the UV-Vis absorbance of Dox in the washed-away supernatant, we calculated the drug loading of Dox in the final TSH-SiO 2 @Dox-NPs as $3 \mathrm{w} / \mathrm{w} \%$ and loading efficiency at $45.4 \%$. Moreover, following a similar method, the TSH loading was ascertained as $0.25 \mathrm{w} / \mathrm{w} \%$ by ELISA. Acid-responsive drug delivery would be beneficial for cancer therapy due to the acidic tumor microenvironment. ${ }^{27-30}$ To show the acid-triggered release of Dox from the NPs, TSH-SiO $@$ @Dox-NPs were put into dialysis bags (molecular weight cut-off 3,500 Da) and then incubated in acetate-buffered solution $(\mathrm{pH}=5.0)$ and phosphate-buffered solution (PBS; $\mathrm{pH}=7.4$ ), respectively. These two $\mathrm{pH}$ values at 5.0 and 7.4 could simulate the $\mathrm{pH}$ values in the blood circulation ${ }^{31}$ and within tumor cells. ${ }^{32,33}$
The cumulative release of Dox outside the dialysis bag was then measured by a UV-Vis spectrometer. As shown in Figure 1C, rapid release of Dox at pH 5.0 was achieved. However, at $\mathrm{pH} 7.4$, even at $72 \mathrm{~h}, \sim 40 \%$ loaded Dox was released. The fast release of Dox at $\mathrm{pH} 5.0$ can be attributed to the acid-responsive linkage between Dox and cis-aconitic acid. The slow release of the drug at $\mathrm{pH} 7.4$ as well as the triggered release of payload at $\mathrm{pH} 5.0$ could be beneficial for avoiding premature release, prolonging the blood circulation half-life $\left(t_{1 / 2}\right)$ and eventually delivering more drug to tumor sites.

To show the possible targeting effect of TSH-SiO Dox NPs, the uptake of NPs on Chinese hamster ovary (CHO) cells, both without $\left(\mathrm{CHO} / \mathrm{TSHr}^{-}\right)$and with $(\mathrm{CHO} /$ $\mathrm{TSHr}^{+}$) TSHr, was monitored by flow cytometry through monitoring the fluorescence from Dox. Results in Figure 2A and $\mathrm{B}$ showed that the cellular uptake of TSH-SiO $@$ Dox NPs was greater than that of $\mathrm{SiO}_{2} @$ Dox NPs and on $\mathrm{CHO}$ / $\mathrm{TSHr}^{+}$. However, this was almost the same on the $\mathrm{CHO}$ / $\mathrm{TSHr}^{-}$cells, suggesting TSHr-dependent uptake. To further show the specific binding of TSH-SiO $@$ Dox NPs onto the $\mathrm{CHO} / \mathrm{TSHr}^{+}$cells, free TSH was added to the $\mathrm{CHO} / \mathrm{TSHr}^{+}$ cells to competitively bind to the TSHr and the cell uptake was also tested. Results in Figure $2 \mathrm{C}$ demonstrated that, in the presence of a competitive inhibitor of free TSH, the uptake of $\mathrm{SiO}_{2} @$ Dox and TSH-SiO $@$ @Dox was almost similar, further supporting TSHr-dependent targeting of TSH-SiO $@ @$ Dox.

To visualize the uptake of TSH-SiO $@$ @Dox NPs, imaging of the FTC-133 thyroid cancer cells by confocal laser scanning microscopy (CLSM) was performed (Figure 3A). To visualize the drug Dox (red fluorescence) and the NP simultaneously, the NP was labeled by 5'-FAM (green). Hoechst 33342 stained the cell nucleus (blue). The co-localization of the red and green fluorescence in the cell plasma confirmed the simultaneous uptake of NP with Dox. To quantify this, the uptake of the 5'-FAM-labeled TSH-SiO $@$ Dox NPs by flow cytometry (Figure 3B) showed time-dependent internalization of the NPs of both 5'-FAM (green) and Dox (red) from $30 \mathrm{~min}$ to $3 \mathrm{~h}$, denoting the simultaneous uptake of NPs with Dox. This simultaneous uptake indicates the stability of NPs, with minimal release of Dox before they entered the cells.

To further study the anticancer drug efficacy in vitro, an MTT assay on FTC-133 thyroid cancer cells was performed on Dox, $\mathrm{SiO}_{2} / \mathrm{Dox}$, and $\mathrm{TSH}-\mathrm{SiO}_{2} / \mathrm{Dox}$ (Figure 4A). Compared to the cell viability curve of Dox, the cell viability curve of $\mathrm{SiO}_{2} / \mathrm{Dox}$ shifted down, indicating the higher potency of $\mathrm{SiO}_{2} /$ Dox. Moreover, $\mathrm{TSH}-\mathrm{SiO}_{2} / \mathrm{Dox}$ showed greatest toxicity toward FTC-133 cells. This could be due to the targeting effect of TSH. Further, the $\mathrm{IC}_{50}$ values can be calculated on the basis of the cell viability curve. The $\mathrm{IC}_{50}$ values of Dox, 
A<smiles>CC1OC(OCC23CC(O)(C(=O)O)CC2=C(O)C2C(=O)c4ccccc4C(=O)C2C3O)CC(N)C1O</smiles>

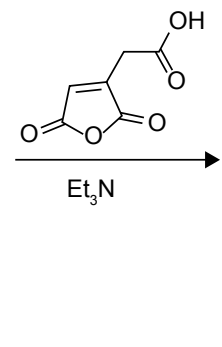

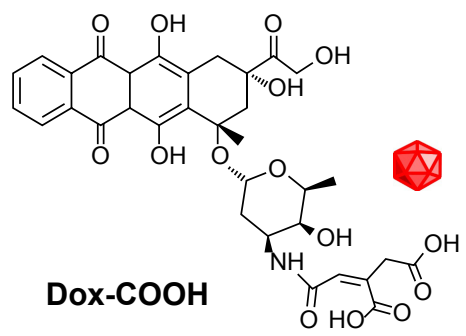

B

PDP-PEG-NHS
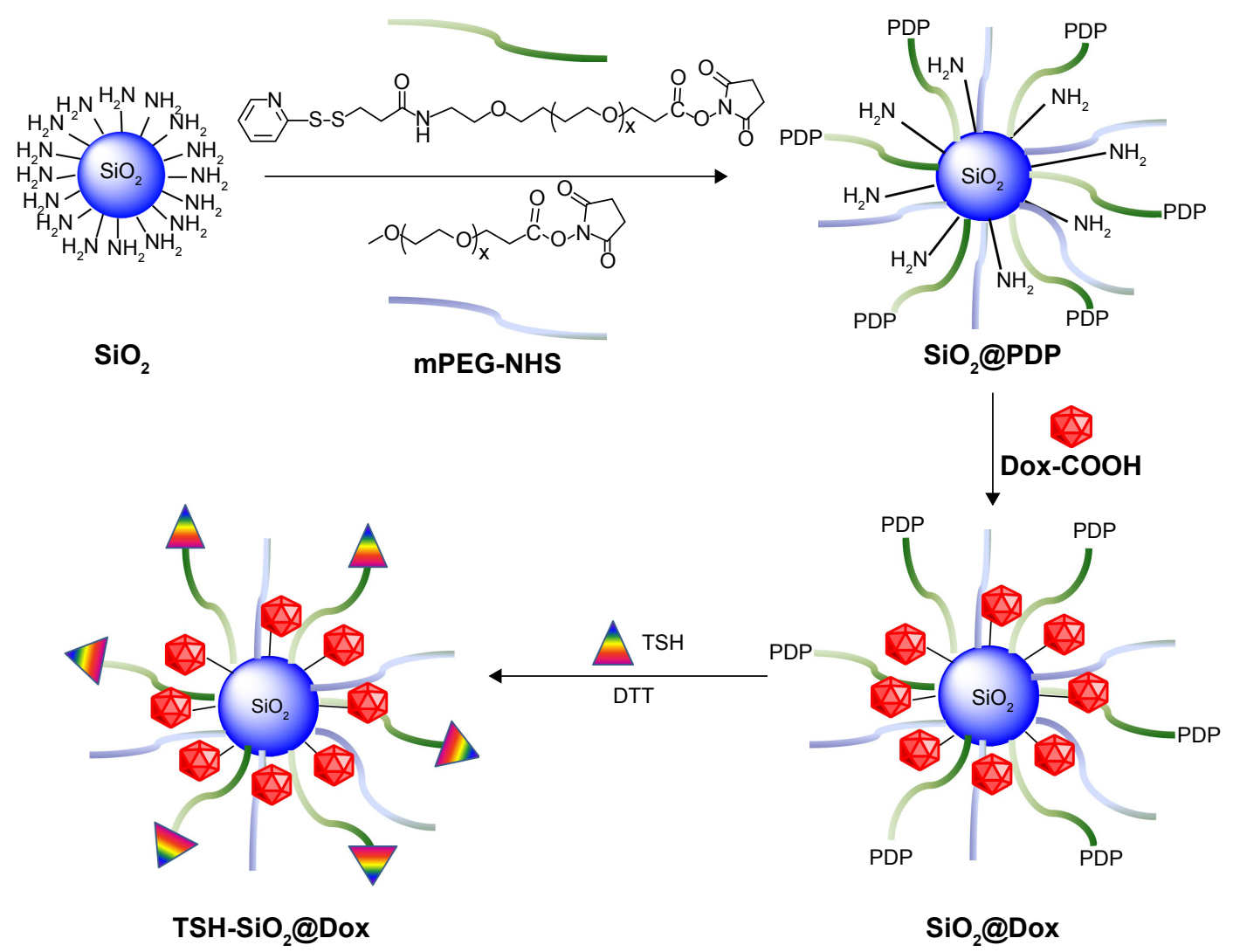

Scheme I Synthesis of Dox prodrug and preparation of thyroid-targeting NPs TSH-SiO @Dox. Dox was firstly conjugated with cis-aconitic anhydride to prepare Dox$\mathrm{COOH}(\mathbf{A})$. $\mathrm{SiO}_{2}$ was PEGylated with mPEG-NHS and PDP-PEG-NHS. PEGylated $\mathrm{SiO}_{2}$ with PDP groups $\left(\mathrm{SiO}_{2} @ P D P\right)$ was further conjugated with Dox and TSH. Targeted NPs with Dox and TSH ligand (TSH-SiO @Dox) were prepared in this way (B).

Abbreviations: Dox, doxorubicin; DTT, dithiothreitol; mPEG-NHS, Succinimidyl carboxyl methyl ester; NP, nanoparticle; PDP-PEG-NHS, orthopyridyl disulfide PEG Succinimidyl ester; PDP, orthopyridyl disulfide; PEG, polyethylene glycol; $\mathrm{SiO}_{2}$, silicon dioxide; TSH, thyroid-stimulating hormone.

A

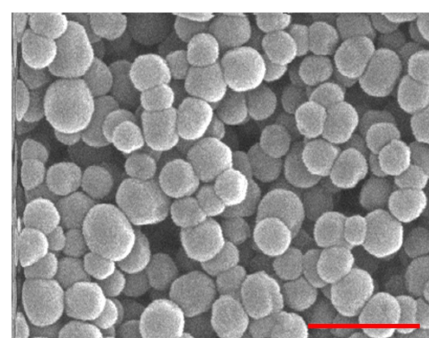

B

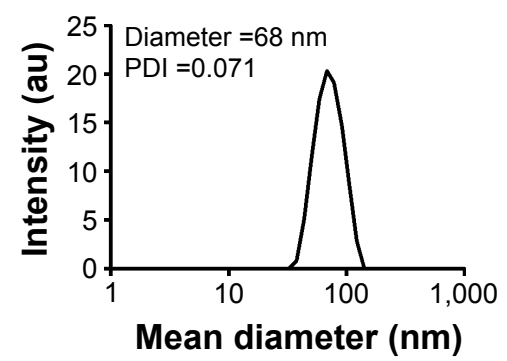

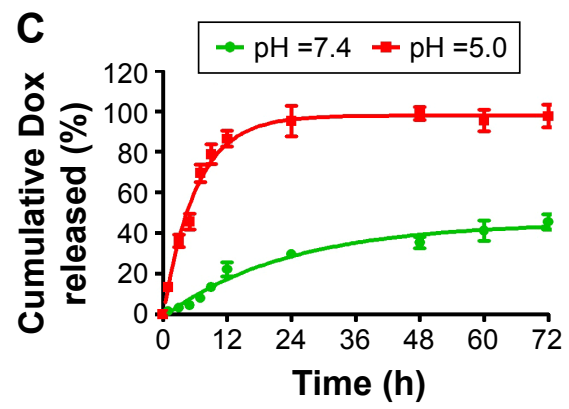

Figure I Characterization of TSH-SiO,@Dox. Representative TEM image (A) and DLS curve (B) of TSH-SiO,@Dox NPs. Scale bar =I00 nm. Due to the presence of cis-aconitic linkage between the $\mathrm{SiO}_{2}$ and Dox, release of Dox can be triggered by the acidic environment in tumor cells, which was simulated by the acid-triggered drug release as shown in $(\mathbf{C})$.

Abbreviations: DLS, dynamic light scattering; Dox, doxorubicin; NP, nanoparticle; PDI, polydispersity index; $\mathrm{SiO}_{2}$, silicon dioxide; TEM, transmission electron microscopy; $\mathrm{TSH}$, thyroid-stimulating hormone. 
A

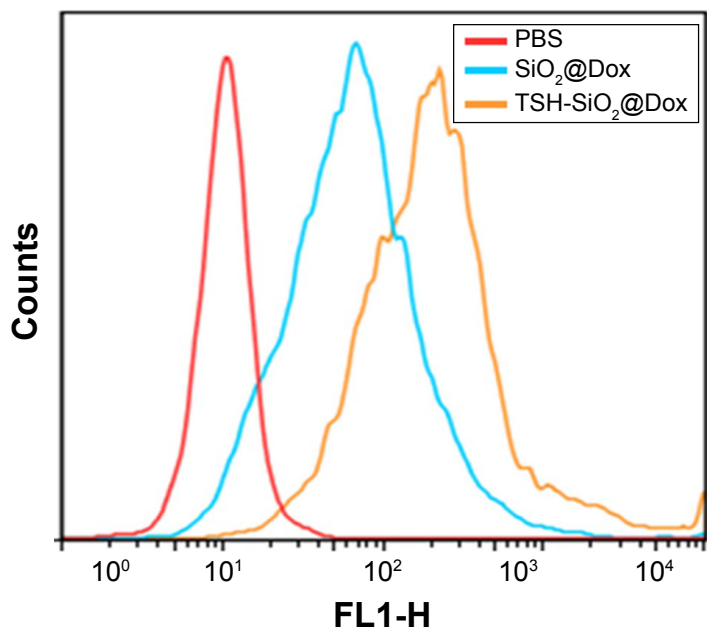

FL1-H

B

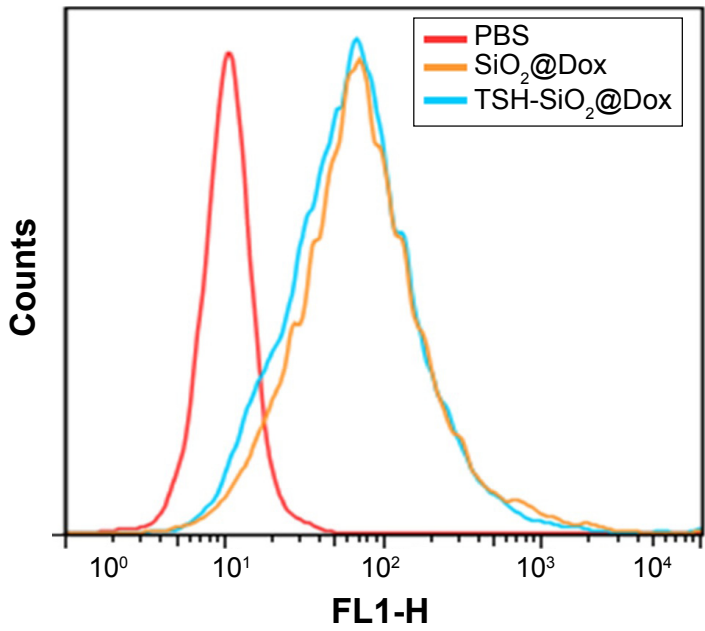

C

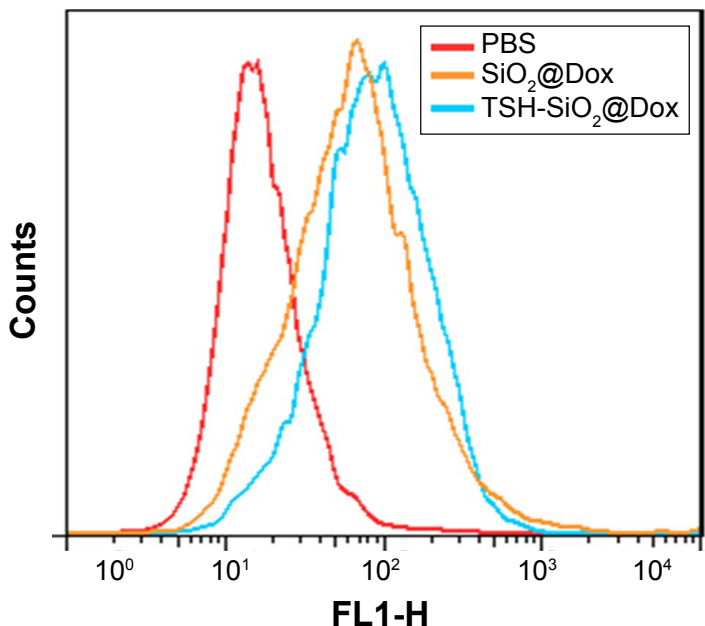

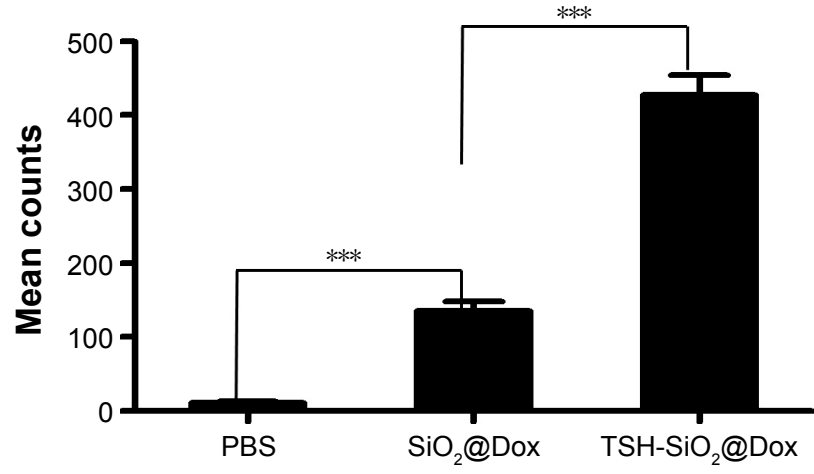
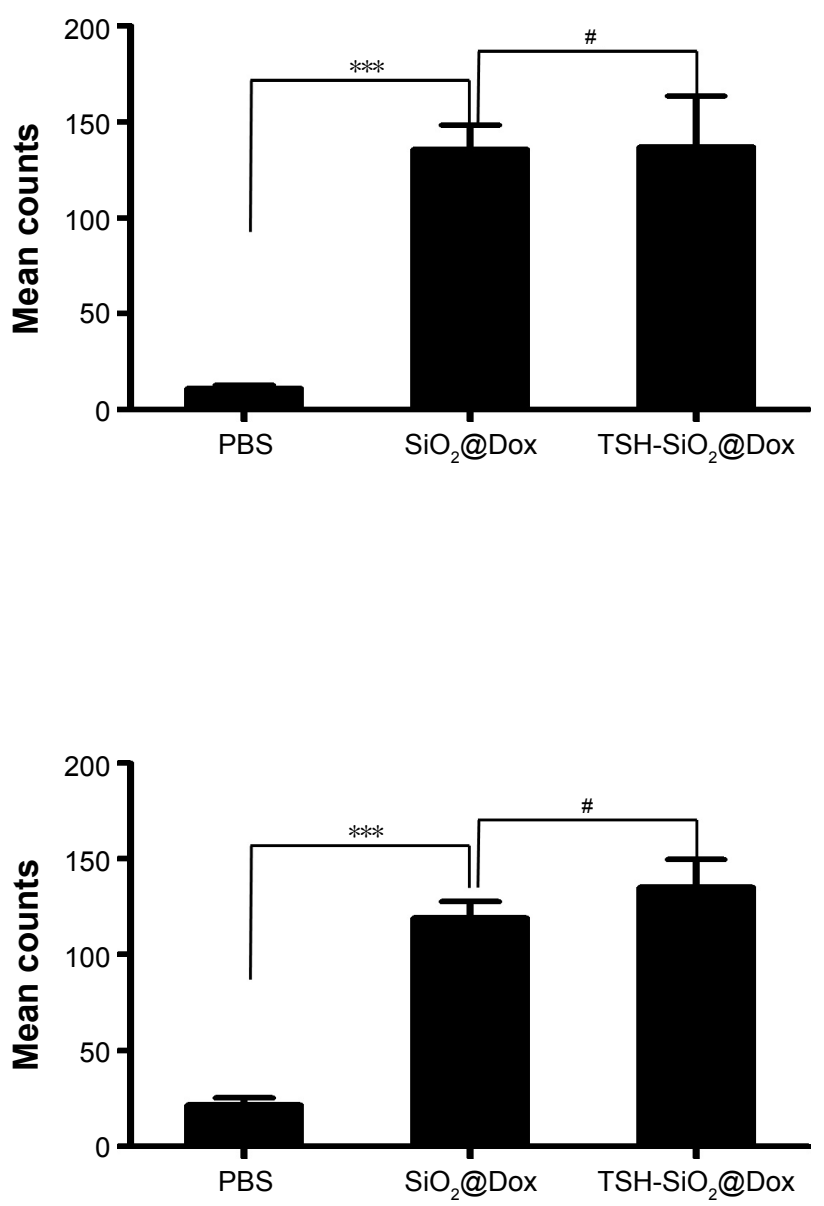

Figure 2 Targeting effect of TSH-SiO @ @Dox NPs. Monitoring targeting effect of TSH-SiO $@$ @ox by flow cytometry as compared to SiO @ @ox uptake by $\mathrm{CHO}_{2} / \mathrm{TSH} \mathrm{r}^{+}$ cells (A) and $\mathrm{CHO}_{\mathrm{TSH}}{ }^{-}$cells (B). To show the targeting effect, free TSH was added to the cells to competitively bind to the TSHr. In the presence of TSH, SiO $@$ @ox and TSH-SiO $@$ Dox showed minimal difference in uptake $(\mathbf{C})$. Data are shown as mean $\pm \mathrm{SD}(\mathrm{n}=3)$. Significance is defined by ${ }^{\#} P>0.05$ and $* * * P<0.00 \mathrm{I}$.

Abbreviations: $\mathrm{CHO}$, Chinese hamster ovary; $\mathrm{CHO} / \mathrm{TSHr}^{-}, \mathrm{CHO}$ cells without $\mathrm{TSHr}$; $\mathrm{CHO} / \mathrm{TSHr}^{+}$, $\mathrm{CHO}$ cells with $\mathrm{TSHr}$; Dox, doxorubicin; $\mathrm{NP}$, nanoparticle; PBS, phosphate buffered saline; $\mathrm{SD}$, standard deviation; $\mathrm{SiO}_{2}$, silicon dioxide; $\mathrm{TSH}$, thyroid-stimulating hormone; $\mathrm{TSHr}$, TSH receptor. 


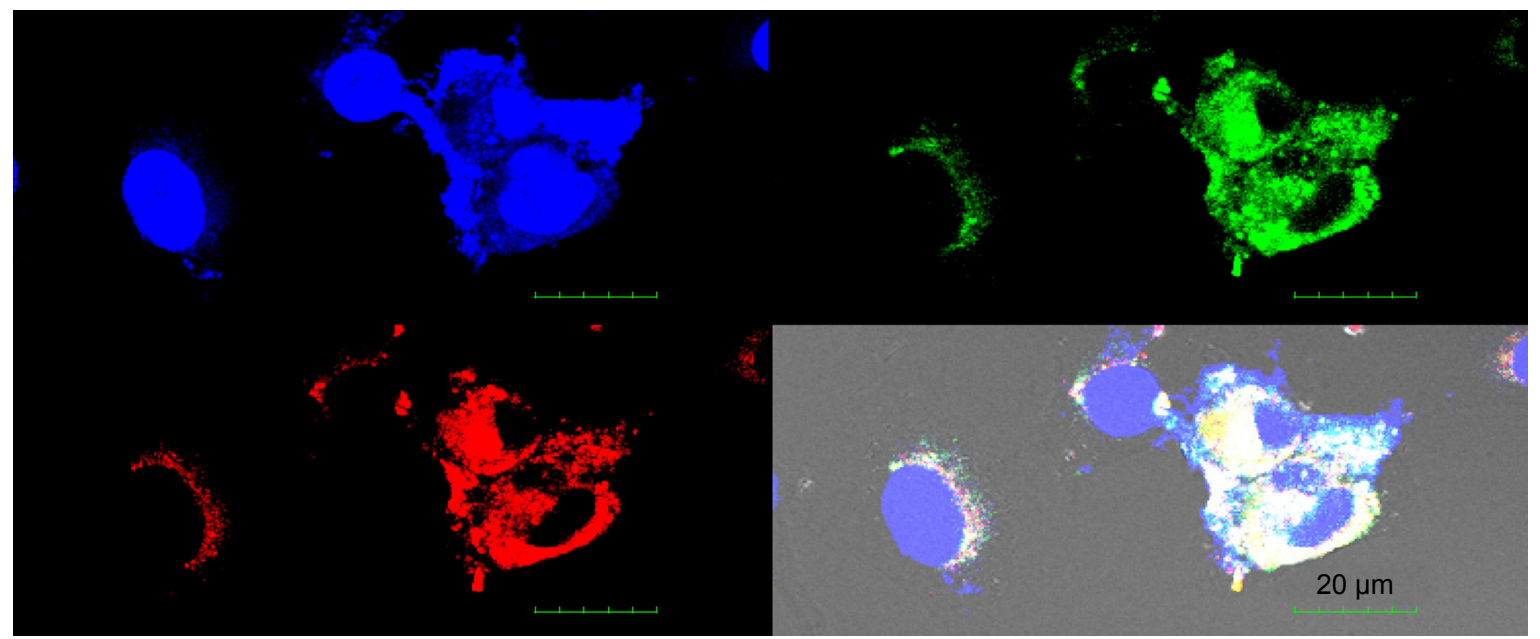

B

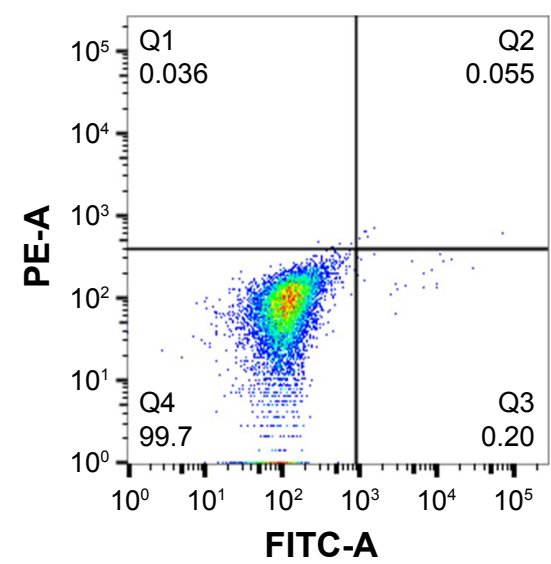

$30 \mathrm{~min}$

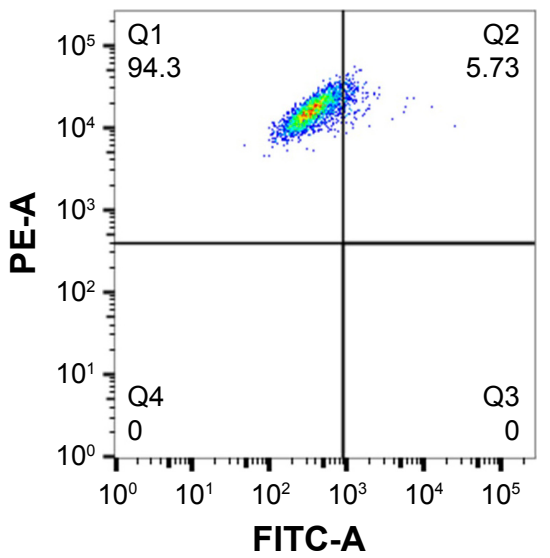

$3 \mathrm{~h}$

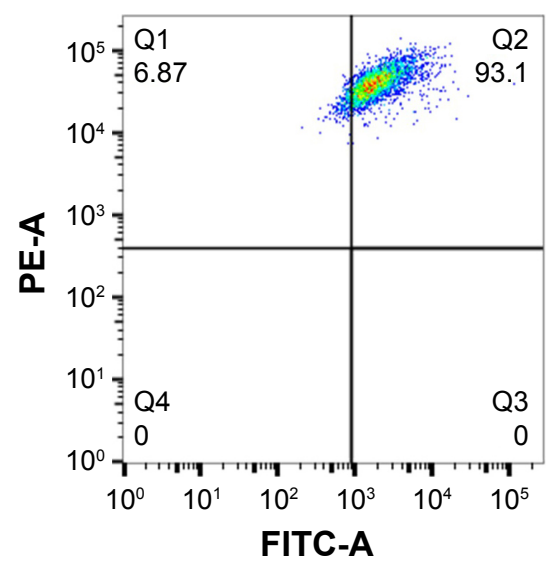

Figure $3 \mathrm{~A}$ study of the uptake of TSH-SiO $/$ Dox $/ 5^{\prime}$-FAM. Confocal laser scanning of cells treated with TSH-SiO $/ \mathrm{Dox}_{2} / 5^{\prime}$-FAM after $3 \mathrm{~h}$. The targeting NPs were labeled by $5^{\prime}$-FAM (green). Hoechst stained the cell nucleus. Red fluorescence came from Dox. Scale bars $=20 \mu M(\mathbf{A})$. To quantitatively monitor the NPs and the drug, cells were treated with $\mathrm{TSH}-\mathrm{SiO}_{2} / \mathrm{Dox} / 5^{\prime}$-FAM, and then red and green fluorescence were monitored by flow cytometry. PBS-treated group (left), TSH-SiO $@$ @Dox/5'-FAM-treated group at $30 \mathrm{~min}$ (middle) and $3 \mathrm{~h}$ (right) (B).

Abbreviations: 5'-FAM, 5-carboxyfluorescein; Dox, doxorubicin; NP, nanoparticle; PBS, phosphate buffered saline; $\mathrm{SiO}_{2}$, silicon dioxide; TSH, thyroid-stimulating hormone.

$\mathrm{SiO}_{2} / \mathrm{Dox}$, and $\mathrm{TSH}-\mathrm{SiO}_{2} /$ Dox on FTC-133 cells were 2.32, 0.96 , and $0.32 \mu \mathrm{M}$, respectively. Targeted $\mathrm{NPs} \mathrm{TSH}-\mathrm{SiO}_{2} /$ Dox increased the potency of Dox $\sim 7.3$-fold, whereas this was only $\sim 3$-fold for the non-targeted $\mathrm{NPs} \mathrm{SiO}_{2} / \mathrm{Dox}$, clearly suggesting the benefit of TSH targeting. Subsequently, clonogenic assay assessment of the reproductive viability and colony-forming ability was performed on cells treated with Dox, $\mathrm{SiO}_{2} /$ Dox, and TSH-SiO$/$ Dox, with PBS as a control. As shown in Figure 4B, all drug-treated groups including Dox, $\mathrm{SiO}_{2} / \mathrm{Dox}$, and $\mathrm{TSH}-\mathrm{SiO}_{2} /$ Dox showed less formation of colonies. Moreover, $\mathrm{TSH}-\mathrm{SiO}_{2} / \mathrm{Dox}$ had less colonies than Dox- and $\mathrm{SiO}_{2} /$ Dox-treated cells, further indicating the greater potency of $\mathrm{TSH}-\mathrm{SiO}_{2} / \mathrm{Dox}$ via tumor targeting.

Doxorubicin acts through topoisomerase II inhibition and free radical generation, eventually inducing apoptosis. ${ }^{34}$ To compare the apoptosis-inducing effect of Dox, $\mathrm{SiO}_{2} / \mathrm{Dox}$, and $\mathrm{TSH}-\mathrm{SiO}_{2} /$ Dox, FTC-133 thyroid cells were treated with these drugs at an equal concentration of Dox. As shown in Figure 4C and D, Dox induced an apoptosis rate of $29.6 \%$, whereas this was $45.3 \%$ and $79.0 \%$ for $\mathrm{SiO}_{2} / \mathrm{Dox}$ and $\mathrm{TSH}-\mathrm{SiO}_{2} /$ Dox respectively, indicating the advantage of TSH-SiO $/$ Dox over Dox and $\mathrm{SiO}_{2} /$ Dox.

Finally, to show the benefits of TSH-mediated targeting of TSH-SiO 2 /Dox on the thyroid cancers, an FTC-133 subcutaneous xenograft model was established. Mice were intravenously injected three times (days 0, 6, and 12) with either PBS or the agents Dox, $\mathrm{SiO}_{2} @$ Dox, and TSH-SiO $/$ Dox respectively. The drug Dox dose for mice was $5 \mathrm{mg}$ Dox/kg body weight. Subsequently, the tumor burden and relative body-weight change were monitored every other day. At day 21, the mice were euthanized and the tumors in each group were collected and weighed. As shown in Figure 5A, 
A

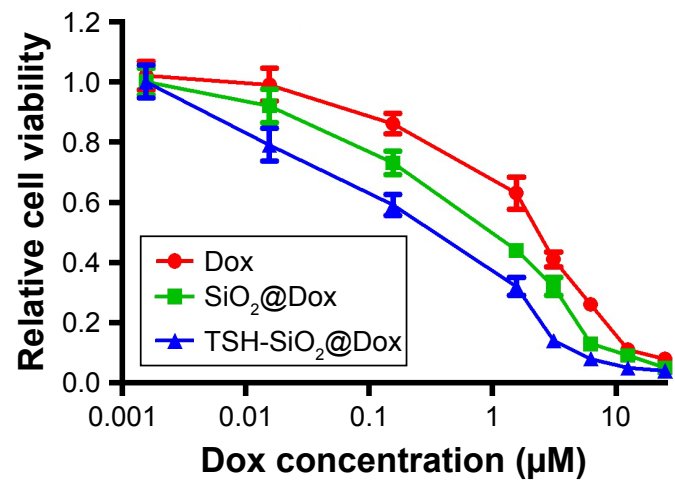

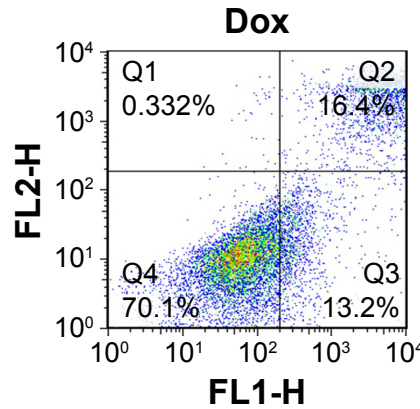

FL1-H

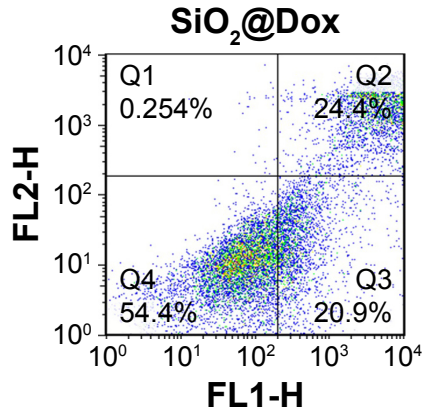

PBS
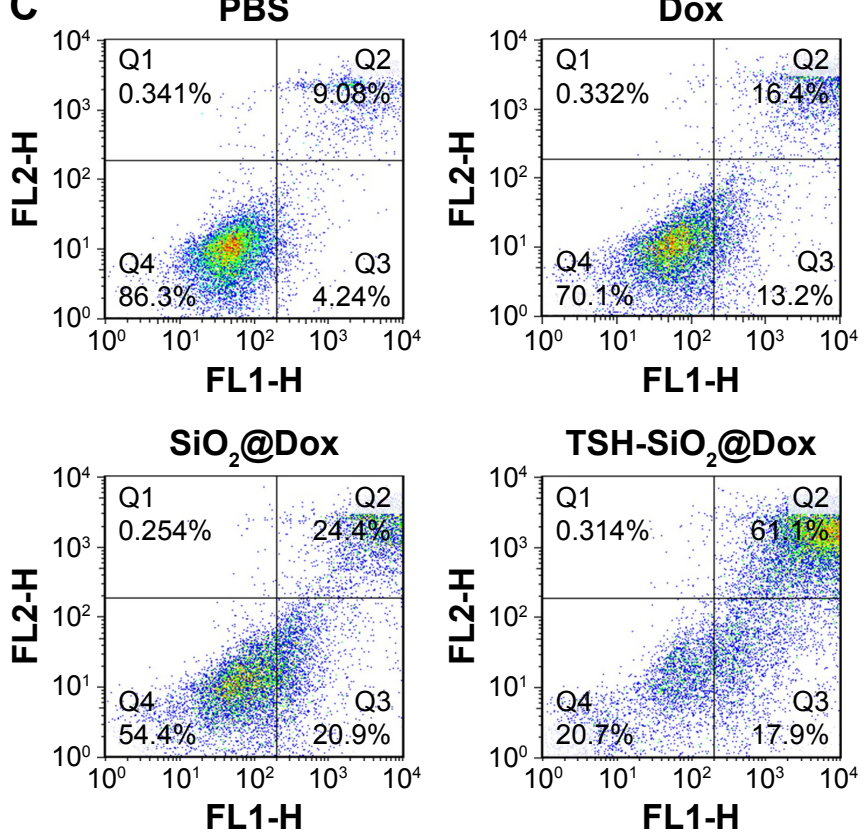

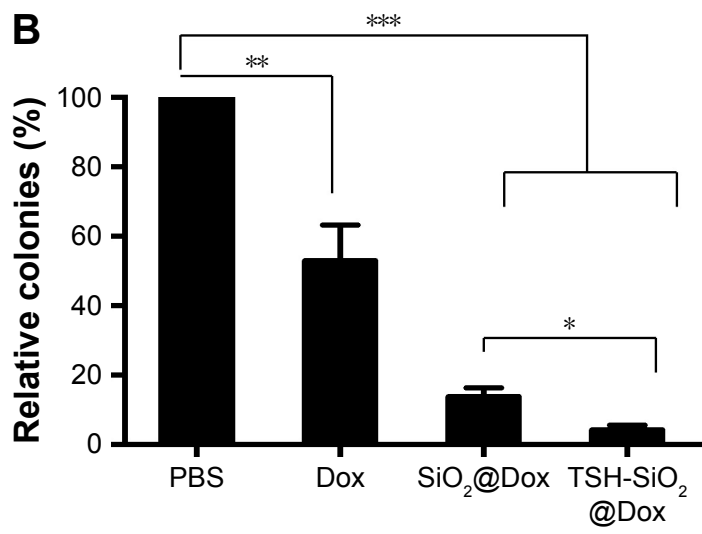

D

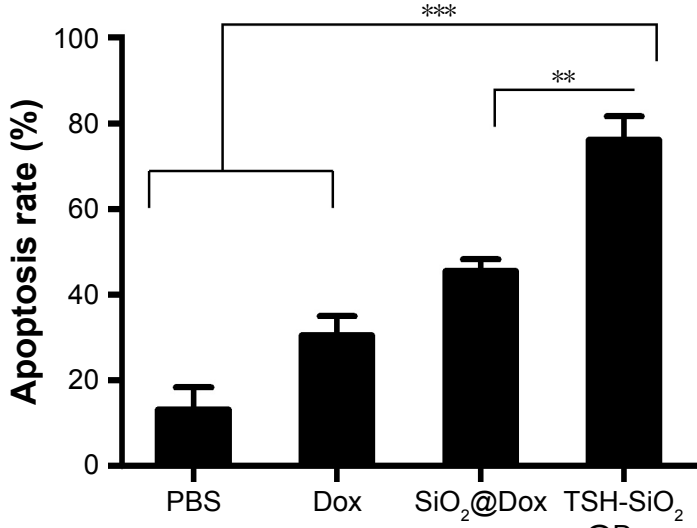

@Dox

Figure 4 In vitro evaluation of the anticancer efficacy of $\mathrm{TSH}_{-} \mathrm{SiO}_{2} @ \mathrm{Dox}$ on thyroid cancer cells. Cell viability curve of Dox, SiO $@$ @Dox, and TSH-SiO $/ \mathrm{Dox}$ at $72 \mathrm{~h}(\mathbf{A})$ and relative cell colonies formation by cells treated with Dox, SiO $@$ Dox, and TSH-SiO $/$ Dox, respectively, at an equal Dox concentration at $0.05 \mu M$ (B). (C and $\mathbf{D}$ ) Apoptosis rate of the cells treated with Dox, $\mathrm{SiO}_{2} @ \mathrm{Dox}$, and $\mathrm{TSH}-\mathrm{SiO}_{2} / \mathrm{Dox}$. Data shown as mean $\pm \mathrm{SD}(\mathrm{n}=3)$. Significance is defined by $* P<0.05$, $* * P<0.0 \mathrm{I}$, and $* * * P<0.001$.

Abbreviations: Dox, doxorubicin; NP, nanoparticle; PBS, phosphate buffered saline; SD, standard deviation; $\mathrm{SiO}_{2}$, silicon dioxide; TSH, thyroid-stimulating hormone.

tumors in PBS-treated mice grew very rapidly. At the end of this study, tumor size was $>3,500 \mathrm{~mm}^{3}$. Dox-treated mice showed lesser tumor growth compared to the PBS group; at the endpoint, tumor size was $\sim 1,500 \mathrm{~mm}^{3}$. However, $\mathrm{SiO}_{2} @$, Dox showed a slightly better antitumor effect in the FTC-133 cancer model. Last, but not the least, tumor growth in the $\mathrm{TSH}-\mathrm{SiO}_{2} /$ Dox-treated mice was almost arrested. This result indicated the greater tumor inhibitory ability of $\mathrm{TSH}-\mathrm{SiO}_{2} /$ Dox. This is possibly due to the targeting effect of TSH on the NPs. Conventional chemotherapeutic agents are known to bring great side effects to animals and human beings. To assess side effects caused by drug treatment, the body weight of the mice in each group was monitored. As shown in Figure 5B, the body weight of the PBS-treated group increased. To quantify antitumor efficacy, at the end of study, all mice were sacrificed and the tumors were collected. The mass in each group is shown in Figure 5C. Mice treated with Dox showed a mean tumor weight of $2.3 \mathrm{~g}$, compared to that of $4.23 \mathrm{~g}$ in mice treated with PBS. TSH-SiO $/$ Dox-treated mice showed a tumor weight of $0.78 \mathrm{~g}$, which was $<1.45 \mathrm{~g}$ that of the $\mathrm{SiO}_{2} /$ Dox-treated group, indicating better antitumor efficacy.

Doxorubicin is known to cause cardiotoxicity. ${ }^{35-38}$ To unveil whether the NP formulation shifts toxicity, blood CK values were evaluated in the mice treated with PBS, Dox, $\mathrm{SiO}_{2} @$ Dox, and TSH-SiO $/$ Dox, respectively. As shown in 

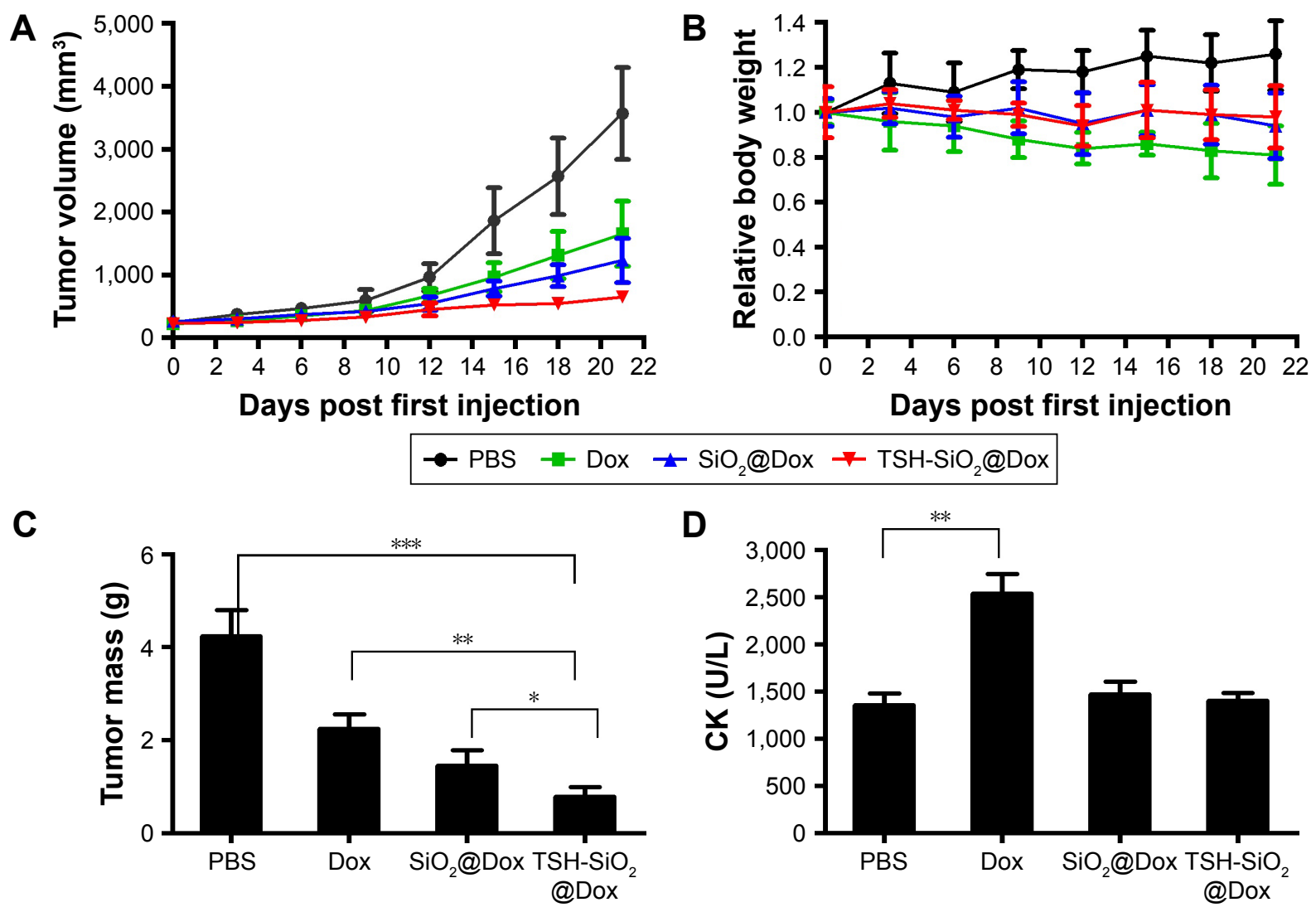

Figure 5 In vivo evaluation of $\mathrm{TSH}-\mathrm{SiO}_{2} / \mathrm{Dox}$ on FTC-I 33 xenograft model. Tumor shrinkage by $\mathrm{TSH}-\mathrm{SiO}_{2} / \mathrm{Dox}_{\text {as }}$ compared to PBS, Dox, and $\mathrm{SiO} / \mathrm{Dox}$-treated mice ( $\mathrm{n}=5$, each group). Mice were intravenously injected with either PBS (PBS group) or an equal Dox dose of $5 \mathrm{mg} / \mathrm{kg}$ body weight (drug-treatment groups) on days 0,6 , and I2 (A). The body weight change of the mice is shown in B. At the end of this study, mice were sacrificed and tumors were collected and weighed (C). Cardiotoxicity as indicated by the $C K$ is shown in $\mathbf{D}$. Significance is defined by $* P<0.05$, $* * P<0.01$, and $* * * P<0.001$.

Abbreviations: CK, creatinine kinase; Dox, doxorubicin; NP, nanoparticle; PBS, phosphate buffered saline; SD, standard deviation; SiO, silicon dioxide; TSH, thyroidstimulating hormone.

Figure 5D, Dox-treated mice showed significantly higher $\mathrm{CK}$ values, indicating greater cardiotoxicity. However, both $\mathrm{SiO}_{2} @$ Dox- and TSH-SiO $/$ Dox-treated mice showed lower CK values, which are comparable to those in PBS-treated mice group. This indicated the lower cardiotoxicity induced by these two treatments, suggesting the ability of $\mathrm{SiO}_{2} \mathrm{NP}$ to reduce toxicity.

\section{Conclusion}

Here we showed the possible targeting ${ }^{39}$ of thyroid cancer by constructing a TSH-loaded NP delivery system with Dox. By introducing an acid-liable linker between Dox and the NP, acid-triggered release of Dox was achieved. TSH can be attached onto the surface of the NPs by disulfide bond formation. This $\mathrm{TSH}-\mathrm{SiO}_{2} / \mathrm{Dox}$ preferentially accumulates in the $\mathrm{TSHr}^{+}$cells for targeting thyroid cancers. We then showed cancer targeting by confocal laser scanning microscopy as well as better in vitro anticancer efficacy of TSH-SiO $/$ /Dox over free Dox and non-targeted NPs. This enhanced efficacy was further proved by a greater ability to inhibit the cancer cell colony-formation assay and elevated apoptosis. Further in vivo evaluation of $\mathrm{TSH}-\mathrm{SiO}_{2} / \mathrm{Dox}$ confirmed the possible targeting effect of $\mathrm{TSH}-\mathrm{SiO}_{2} / \mathrm{Dox}$ on thyroid cancers, with better tumor inhibition rate and lower toxicity, which opens the door for the treatment of thyroid cancer in the clinic.

\section{Acknowledgment}

The authors gratefully acknowledge the support from the Youth Foundation of the Science and Technology Department of Jilin province (\#201201046).

\section{Disclosure}

The authors report no conflicts of interest in this work.

\section{References}

1. Lam KY, Lo CY. Metastatic tumors of the thyroid gland: a study of 79 cases in Chinese patients. Arch Pathol Lab Med. 1998;122(1): 37-41.

2. Chen H, Nicol TL, Udelsman R. Clinically significant, isolated metastatic disease to the thyroid gland. World J Surg. 1999;23(2):177-180. 
3. Roka S, Kornek G, Schüller J, Ortmann E, Feichtinger J, Armbruster C. Carcinoma showing thymic-like elements - a rare malignancy of the thyroid gland. Br J Surg. 2004;91(2):142-145.

4. Mazzaferri EL, Kloos RT. Clinical review 128: current approaches to primary therapy for papillary and follicular thyroid cancer. J Clin Endocrinol Metab. 2001;86(4):1447-1463.

5. Fard-Esfahani A, Emami-Ardekani A, Fallahi B, et al. Adverse effects of radioactive iodine-131 treatment for differentiated thyroid carcinoma. Nucl Med Commun. 2014;35(8):808-817.

6. Willegaignon J, Sapienza M, Ono C, et al. Outpatient radioiodine therapy for thyroid cancer: a safe nuclear medicine procedure. Clin Nucl Med. 2011;36(6):440-445.

7. Sherman SI. Thyroid carcinoma. Lancet. 2003;361(9356):501-511.

8. Ain KB. Anaplastic thyroid carcinoma: behavior, biology, and therapeutic approaches. Thyroid. 1998;8(8):715-726.

9. Neumann S, Huang W, Titus S, et al. Small-molecule agonists for the thyrotropin receptor stimulate thyroid function in human thyrocytes and mice. Proc Natl Acad Sci US A. 2009;106(30):12471-12476.

10. Pujol-Borrell R, Giménez-Barcons M, Marín-Sanchez A, Colobran R. Genetics of Graves' disease: special focus on the role of TSHR gene. Horm Metab Res. 2015;47(10):753-766.

11. Dorsam RT, Gutkind JS. G-protein-coupled receptors and cancer. Nat Rev Cancer. 2007;7(2):79-94.

12. Yamamoto Y, Sakamoto M, Fujii G, et al. Overexpression of orphan G-protein-coupled receptor, Gpr49, in human hepatocellular carcinomas with beta-catenin mutations. Hepatology. 2003;37(3):528-533.

13. Yu Y, Zhang Q, Buscaglia J, et al. Quantitative real-time detection of carcinoembryonic antigen (CEA) from pancreatic cyst fluid using 3-D surface molecular imprinting. Analyst. 2016;141(14):4424-4431.

14. Paolino D, Cosco D, Gaspari M, et al. Targeting the thyroid gland with thyroid-stimulating hormone (TSH)-nanoliposomes. Biomaterials. 2014; 35(25):7101-7109.

15. Gao XJ, Li AQ, Zhang X, Liu P, Wang JR, Cia X. Thyroid-stimulating hormone (TSH)-armed polymer-lipid nanoparticles for the targeted delivery of cisplatin in thyroid cancers: therapeutic efficacy evaluation. Rsc Adv. 2015;5:106413-106420.

16. Yu Y, Zhang Q, Chang CC, et al. Design of a molecular imprinting biosensor with multi-scale roughness for detection across a broad spectrum of biomolecules. Analyst. 2016;141(19):5607-5617.

17. Sun H, Guo B, Cheng R, Meng F, Liu H, Zhong Z. Biodegradable micelles with sheddable poly(ethylene glycol) shells for triggered intracellular release of doxorubicin. Biomaterials. 2009;30(31):6358-6366.

18. Chen W, Meng F, Cheng R, Zhong Z. pH-Sensitive degradable polymersomes for triggered release of anticancer drugs: a comparative study with micelles. J Control Release. 2010;142(1):40-46.

19. Wang S, Shang L, Li L, et al. Metal-organic-framework-derived mesoporous carbon nanospheres containing porphyrin-like metal centers for conformal phototherapy. Adv Mater. 2016;28(38):8379-8387.

20. Fang WJ, Yang J, Gong JW, Zheng N. Photo- and pH-triggered release of anticancer drugs from mesoporous silica-coated Pd@Ag nanoparticles. Adv Funct Mater. 2012;22:842-848.

21. Ahmed F, Pakunlu RI, Srinivas G, et al. Shrinkage of a rapidly growing tumor by drug-loaded polymersomes: $\mathrm{pH}$-triggered release through copolymer degradation. Mol Pharm. 2006;3(3):340-350.

22. Liu J, Bu W, Pan L, Shi J. NIR-triggered anticancer drug delivery by upconverting nanoparticles with integrated azobenzene-modified mesoporous silica. Angew Chem Int Ed Engl. 2013;52(16):4375-4379.

23. Oh KT, Oh YT, Oh NM, Kim K, Lee DH, Lee ES. A smart flower-like polymeric micelle for $\mathrm{pH}$-triggered anticancer drug release. Int J Pharm. 2009;375(1-2):163-169.
24. He CF, Wang SH, Yu YJ, et al. Advances in biodegradable nanomaterials for photothermal therapy of cancer. Cancer Biol Med. 2016;13(3): 299-312.

25. Naskar J, Palui G, Banerjee A. Tetrapeptide-based hydrogels: for encapsulation and slow release of an anticancer drug at physiological $\mathrm{pH}$. J Phys Chem B. 2009;113(35):11787-11792.

26. Du C, Deng D, Shan L, et al. A pH-sensitive doxorubicin prodrug based on folate-conjugated BSA for tumor-targeted drug delivery. Biomaterials. 2013;34(12):3087-3097.

27. Liu DF, Bernuz CR, Fan J, et al. A nano-in-nano vector: merging the best of polymeric nanoparticles and drug nanocrystals. Adv Funct Mater. 2017; 27(9):1604508.

28. Liu D, Zhang H, Cito S, et al. Core/shell nanocomposites produced by superfast sequential microfluidic nanoprecipitation. Nano Lett. 2017; 17(2):606-614.

29. Liu D, Zhang H, Mäkilä E, et al. Microfluidic assisted one-step fabrication of porous silicon@acetalated dextran nanocomposites for precisely controlled combination chemotherapy. Biomaterials. 2015;39: 249-259.

30. Liu D, Zhang H, Herranz-Blanco B, et al. Microfluidic assembly of monodisperse multistage $\mathrm{pH}$-responsive polymer/porous silicon composites for precisely controlled multi-drug delivery. Small. 2014; 10(10):2029-2038

31. Li Y, Xiao W, Xiao K, et al. Well-defined, reversible boronate crosslinked nanocarriers for targeted drug delivery in response to acidic $\mathrm{pH}$ values and cis-diols. Angew Chem Int Ed Engl. 2012;51(12):2864-2869.

32. Vaupel P, Kallinowski F, Okunieff P. Blood flow, oxygen and nutrient supply, and metabolic microenvironment of human tumors: a review. Cancer Res. 1989;49(23):6449-6465.

33. Sawant RM, Hurley JP, Salmaso S, et al. "SMART" drug delivery systems: double-targeted $\mathrm{pH}$-responsive pharmaceutical nanocarriers. Bioconjug Chem. 2006;17(4):943-949.

34. Deng S, Yan T, Jendrny C, et al. Dexrazoxane may prevent doxorubicininduced DNA damage via depleting both topoisomerase II isoforms. BMC Cancer. 2014;14:842.

35. Olson RD, Mushlin PS. Doxorubicin cardiotoxicity: analysis of prevailing hypotheses. FASEB J. 1990;4(13):3076-3086.

36. Olson RD, Mushlin PS, Brenner DE, et al. Doxorubicin cardiotoxicity may be caused by its metabolite, doxorubicinol. Proc Natl Acad Sci US A. 1988;85(10):3585-3589.

37. Arola OJ, Saraste A, Pulkki K, Kallajoki M, Parvinen M, VoipioPulkki LM. Acute doxorubicin cardiotoxicity involves cardiomyocyte apoptosis. Cancer Res. 2000;60(7):1789-1792.

38. Kalyanaraman B, Joseph J, Kalivendi S, Wang S, Konorev E, Kotamraju S. Doxorubicin-induced apoptosis: implications in cardiotoxicity. Mol Cell Biochem. 2002;234-235(1-2):119-124.

39. Polegato BF, Minicucci MF, Azevedo PS, et al. Acute doxorubicininduced cardiotoxicity is associated with matrix metalloproteinase-2 alterations in rats. Cell Physiol Biochem. 2015;35(5):1924-1933.

40. Tomayko MM, Reynolds CP. Determination of subcutaneous tumor size in athymic (nude) mice. Cancer Chemother Pharmacol. 1989;24(3): $148-154$.

41. O'Donoghue JA, Bardiès M, Wheldon TE. Relationships between tumor size and curability for uniformly targeted therapy with beta-emitting radionuclides. J Nucl Med. 1995;36(10):1902-1909.

42. Hermann PC, Huber SL, Herrler T, et al. Distinct populations of cancer stem cells determine tumor growth and metastatic activity in human pancreatic cancer. Cell Stem Cell. 2007;1(3):313-323. 
International Journal of Nanomedicine

Dovepress

\section{Publish your work in this journal}

The International Journal of Nanomedicine is an international, peerreviewed journal focusing on the application of nanotechnology in diagnostics, therapeutics, and drug delivery systems throughou the biomedical field. This journal is indexed on PubMed Central, MedLine, CAS, SciSearch ${ }^{\circledR}$, Current Contents ${ }^{\circledR} /$ Clinical Medicine,
Journal Citation Reports/Science Edition, EMBase, Scopus and the Elsevier Bibliographic databases. The manuscript management system is completely online and includes a very quick and fair peer-review system, which is all easy to use. Visit http://www.dovepress.com/ testimonials.php to read real quotes from published authors.

Submit your manuscript here: http://www.dovepress.com/international-journal-of-nanomedicine-journal 